\title{
A ciência da informação: novos rumos sociais para um pensar reconstrutivo no mundo contemporâneo
}

\author{
Mirian de Albuquerque Aquino \\ Doutora em educação \\ Universidade Federal do Rio Grande do Norte \\ E-mail: miriabu@uol.com.br
}

\section{RESUMO}

\begin{abstract}
0 texto procura situar a ciência da informação (CI) no atual cenário da sociedade da informação e do conhecimento, explicitando os novos processos informacionais que decorrem da emergência das tecnologias da informação e comunicação e as pressões exercidas para uso de serviços e produtos. Aborda o novo papel da $\mathrm{Cl}$ diante dos novos rumos das ciências sociais, contribuindo com opções teóricas para reestruturar discursos e práticas de pesquisa na Cl. Aponta estratégias para os indivíduos se adequarem ao novo modelo de desenvolvimento.
\end{abstract}

\section{PALAVRAS- CHAVE}

Sociedade da informação e do conhecimento. Processos informacionais. Pensar reconstrutivo. Ciência da informação (Cl).

\section{Information science in search of new social directions for a reconstructive thinking in the contemporary world}

\section{ABSTRACT}

The text tries to situate Information Science in the present scenario of the information and knowledge society, explaining the new information processes that come from the emergence of Information and Communication Technologies (ICT's) and the pressure over the services and products. It approaches the role of Information Science before the new directions of social sciences, contributing with theoretical choices to restructure discourses and practices of research in Information Science. It points at Information Science's strategies to be adequate to the new model of development.

\section{KEYWORDS}

Information and knowledge society. Information processes. Reconstructive thinking. Information science.

\section{INTRODUÇÃO}

Inserir uma reflexão sobre os novos rumos das ciências sociais e aplicadas na sociedade da informação e do conhecimento e que possa abranger, particularmente, a ciência da informação (CI), implica viver hoje o desafio de situar-nos diante de uma nova fase da história da humanidade, que se caracteriza pelos desafios da globalização das atividades econômicas e da transformação das bases materiais da vida em que as concepções de tempo e espaço já não são mais as mesmas. Trata-se de mutações que reorganizam as sociedades e as articulam em uma complexidade em que a informação e o conhecimento apontam significativas transformações econômicas, (geo) políticas, sociais, culturais e institucionais, cuja dinâmica tem sido impulsionada por "estratégias de acumulação", que contêm no seu cerne processos de geração e difusão de novos conhecimentos.

É um novo tempo que abre passagem para intermináveis fluxos de informação e impõe-nos uma cultura digital atravessada por uma revolução centrada nas tecnologias de informação e comunicação, remodelando a base material da sociedade em ritmo acelerado. São características de uma sociedade da informação e do conhecimento que revelam não só a homogeneidade das formas sociais e de seus processos técnicos, mas também o novo aprendizado a partir do qual o indivíduo desenvolve a sua capacidade de processar todas as formas de informação e transformá-las em conhecimento. São configurações de um novo modo de desenvolvimento (CASTELLS, 1999), amplamente decisivo, do ponto de vista estratégico, não apenas por sua forma de organização em redes, flexibilidade e instabilidade do emprego, individualização da mão-de-obra, mas, principalmente, por colocar o indivíduo diante de uma cultura de virtualidade real construída a partir de um sistema de comunicação onipresente, interligado e altamente sofisticado.

Os indivíduos estão situados em um "paradigma informacional", que resultou do processo de reestruturação capitalista desde os anos de 1980, tendo o capital financeiro como característica central e dependente do conhecimento e da informação, os quais são gerados e aperfeiçoados pela tecnologia da informação. E a era do "capitalismo em rede", ou melhor, é o surgimento de um novo mundo, uma "economia informacional/global [...] 
com capacidade de funcionar como uma unidade em tempo real, em escala planetária” (CASTELLS, 1999, p.110).

Na verdade, arremata Lyotard (1989), estamos em uma pósmodernidade que sinaliza para uma experiência em que as fronteiras culturais e epistemológicas estão a desconstruir as ordens disciplinares para torná-las indistintas. Por sua vez, Jamerson (1996) enfatiza que essas fronteiras estão amplamente relacionadas a três períodos de expansão do capitalismo (mercado ou industrial, monopólio ou imperialismo e pósindustrial) e suas rupturas tecnológicas, cada um marcando uma expansão dialética com o estágio anterior, mas com culturas diferentes, ressaltando-se, no último, o advento das novas tecnologias da informação e comunicação.

Tal imagem remete-nos a uma ciência pós-moderna, em que as condições de conhecimento e tecnologia estão produzindo formas de organização social que desestabilizam os velhos estilos de pensamento e as práticas sociais da modernidade. Nessa perspectiva, a ciência tecnológica e a sua difusão estariam, segundo a visão de Lyotard (1989), privilegiando a diversidade, a localidade, a especificidade e o contingente, criando um mundo onde os sujeitos devem traçar seu próprio caminho, sem ajuda das grandes metanarrativas.

Ao retornar à discussão, Castells (1999) insiste em considerar que a identificação dessa atual sociedade é reconhecida como sociedade da informação e do conhecimento por duas razões: 1) a ampliação de troca de mensagens entre os habitantes do planeta 2) a relevância que adquirem no processo de produção da ciência e da tecnologia. A síntese entre sociedade e conhecimento torna cada vez mais salutar a necessidade de o conhecimento ser aprendido à luz de sua dimensão social. É importante ressaltar que a informação e o conhecimento sempre se constituíram pilares dos diferentes modos de produção social nos diferentes momentos históricos.

Hoje, porém, o conhecimento desempenha papel importante nas relações dos indivíduos, integrando-os em um contexto social contemporâneo cada vez mais complexo, em que a informação e conhecimento passaram a desempenhar estratégico papel em uma sociedade em que

[...] verificam-se novas práticas de produção, comercialização e consumo de bens e serviços, cooperação e competição entre agentes, assim como de circulação e de valorização do capital, a partir da maior intensidade no uso de informação e conhecimento nesses processos (LASTRES; ALBAGLI, 1999, p.8).

A informação, entendida como matéria-prima do conhecimento, adquiriu o status de mercadoria de maior valor nessa sociedade em que a exclusão social, a discriminação, o preconceito, o racismo, a xenofobia e a homofobia estão na ordem do dia. Essa condição pós-moderna, argumenta Baudrillard (1989), citado por Giroux (1993, p. 49), "representaria uma forma de hiper-realidade, uma proliferação infinita de significados, na qual todas as fronteiras confundem-se em modelos de simulação" que substituem os conflitos. Giroux aponta que, para Baudrilard, inexiste a possibilidade de uma epistemologia celebradora das verdades da ciência, capaz de realizar uma leitura profunda dessa nova realidade.

O que o discurso baurillardiniano enuncia é que "são novas formas de tecnologia e informação, as quais têm se tornado centrais à ordem reprodutiva que obscurece as fronteiras entre passado e presente, arte e vida, compromisso e experiência" (GIROUX, 1993, p. 49). Do ponto de vista de Baudrillard, estamos vivendo em uma "sociedade do espetáculo", na qual as massas silenciosas habitam à sombra da marginalização, enquanto os grupos privilegiados "têm lugar através da proliferação de signos, imagens e significados que nos envolvem sem uma indicação de onde vêm nem tampouco do que significam" (GIROUX, 1993, p. 50).

A partir de outra perspectiva, Lyotard (1989) postula que as condições de conhecimento e tecnologia estão produzindo formas de organização social que enfraquecem os antigos modos de pensar, conhecer e agir, pois estamos diante da difusão dos computadores, do conhecimento científico, da tecnologia avançada e dos textos eletrônicos, que priorizam o diverso, o local, o contingente, o circunstancial. As inovações tecnológicas e científicas estão criando um mundo onde os sujeitos têm de desvencilhar-se das velhas fórmulas de análises e interpretações do mundo para buscar seus próprios caminhos.

Em termos do lugar que ocupa a informação na sociedade contemporânea, Lyotard (1989) entende que, nas novas formas de tecnologias, a informação é simplesmente um ruído passivamente engolido pelas massas, porquanto a informação não é interpretada, mas consumida. Nesse admirável mundo novo, sentimos a ausência de uma informação social a partir da qual a universidade e a sociedade, por meio de políticas de informação mais concretas, buscariam, junto ao governo, as saídas para o desenvolvimento de uma informação educacional para a vida inteira (DELORS, 1999), sendo esta permanentemente desafiada pelo novo papel da informação e do conhecimento, como outra forma de as ciências se questionarem. Exigem-se redefinição do papel das ciências sociais e aplicadas e questionamento da informação social que essas ciências produzem, reproduzem e disseminam. Esse ponto de vista nos instiga, como pesquisadores da $\mathrm{CI}$, a percebê-la como uma área que se ocupa da informação especializada, portanto deve reafirmar a necessidade de colocar-se diante de um novo pensar reconstrutivo cotidiano. 


\section{POR UM NOVO PENSAR RECONSTRUTIVO}

A CI, como ciência social inter, multi e transdisciplinar, que se preocupa com os princípios e as práticas da criação, organização e distribuição da informação e com o estudo dos seus fluxos, transmissão e apropriação pelo usuário dessa informação, usando múltiplas formas de disseminação e múltiplos canais, tem sido convocada para assumir significativo papel na sociedade contemporânea: repensar sua responsabilidade social. Isso implicaria deslegitimar a ciência clássica que dita e legisla para produzir nova ciência (MORIN, 1999a), questionar o conhecimento científico produzido procurando refletí-lo nos discursos e nas práticas e compreender as condições de possibilidade de sua existência como um conhecimento social que se propõe a resolver problemas ligados à informação.

A partir dessa perspectiva, Morin (1999a) defende a necessidade da "ciência com consciência", demonstrando os perigos da consciência sem ciência e da ciência sem consciência, pois acredita que essas duas perspectivas sempre terminam sendo mutiladas e mutilantes. Implica a reconstrução do modo de ver o mundo. Um pensar reconstrutivo na $\mathrm{CI}$ supõe o deslocamento de um modo de pensar enraizado nas práticas convencionais, para reescrever uma ciência em uma nova forma, a fim de atingir melhor o alvo social que ela mesma havia colocado desde os seus primórdios (SARACEVIC, 1978).

Essa reconstrução não pressupõe o apagamento ou a anulação do modelo tradicional de fazer ciência e sua relação com documentos impressos e bibliotecas, uma vez que é fundamental preservar a memória, mas essa preservação deve ocorrer a partir do que já se conhece, porque não se parte do nada nem se cria nada, porquanto o que já existe se desenvolveu e se consolidou como conhecimento. É necessário apenas atualizá-lo, reconhecendo que permutar saberes, experimentos e práticas faz parte da capacidade humana criativa. Precisamos problematizar o que já se conhece, fazendo articulação com os enfoques atuais, sem perder de vista o novo papel da informação e do conhecimento na nova sociedade, como seu pano de fundo correspondente, na perspectiva de (re) construir esse conhecimento.

A memória histórica alerta-nos de que não devemos esquecer que a $\mathrm{CI}$ assumiu seu decisivo papel no desenvolvimento da ciência e da tecnologia e que continua a desempenhar a sua função social, hoje acrescida das questões relacionadas aos usuários e suas necessidades de informação, e que as suas novas funções têm sido ampliadas e redesenhadas no novo paradigma tecnológico centrado na informação e no conhecimento. Mas consideramos a necessidade de intensificação das práticas sociais, de compromisso de seus atores sociais: pesquisadores, ensinantes e aprendentes.

Com a emergência das tecnologias da informação e comunicação, a informação prolifera em diversas direções, e todos os campos de conhecimento alimentam-se da informação. Mas é preciso considerar que a CI trata a informação em seus vários suportes (diálogo entre cientistas, comunicação informal, inovação para indústria, patente, fotografia, registro magnético de base de dados e biblioteca virtual, digital eletrônica e na Internet). Essa percepção da concepção de informação na CI especifica-se, ao tomá-la como objeto de estudo. Então, essa informação pode ser estudada em determinada área quanto sob determinada abordagem (PINHEIRO, 2004).

Essa forma de pensar a informação em sua multiplicidade de suportes aprecia o conceito de informação em seu formato múltiplo. Esse ponto de vista conduz à ideia de que não existe sequer um acontecimento, um fenômeno, uma palavra, nem um pensamento cujo sentido não seja múltiplo (DELEUZE; GUATARRI, 1995). Assim sendo, o campo de atuação da CI é múltiplo e suas possibilidades sociais são múltiplas. A CI viaja numa torrente de informação, que foge sem parar, constrói "linhas de fugas" e se desterritorializa. É uma informação "rizomática" (DELEUZE; GUATARRI, 1995).

A informação gera conhecimento nesse contexto das tecnologias da informação e comunicação e traz a necessidade de a CI assumir a sua responsabilidade social para interrogar: Que informação? Para quem? Essas duas questões remetemnos à idéia de informação social em uma sociedade que, em princípio, defende o acesso de todos os cidadãos às redes de comunicação e a necessidade de estarem informados para atender às atuais exigências do mundo tecnológico.

Uma constatação evidente tem sido a de que a informação é elemento-chave para a construção da sociedade baseada na informação (LASTRES;ALBAGLI, 1999), e isso significa que informar, para a sociedade da informação, é muito mais que treinar pessoas para utilizar essas tecnologias. Significa investir no desenvolvimento de competências amplas, que permitam aos indivíduos decidir com base no conhecimento para operar com o uso rotineiro das novas mídias, de modo a ampliar sua capacidade de lidar com a explosão de informações (TAKAHASHI, 2000).

A CI, como uma ciência propulsora do desenvolvimento da capacidade de pensar dos indivíduos e das formas possíveis de intervenção na realidade, encontra crescentemente sua força na possibilidade de uma ação de informação; uma ação social para lidar com situações problemáticas. Assim, trata-se de perceber as comunidades ainda não integradas aos padrões informacionais mínimos, sendo essa ciência desafiada a construir propostas para a formulação de um projeto social próprio, que possa sinalizar para uma política de informação que busque a universalização da informação em todos os níveis.

A globalização coloca, em tela, os grandes problemas brasileiros: a marginalização social, econômica e cultural de grandes parcelas da população. Nesse momento, mais uma categoria entra em 
cena: a marginalização informacional. O Brasil contemporâneo, que pretende se inserir nessa sociedade da informação e do conhecimento, sedimenta uma tendência contínua e desigual, por parte das iniciativas do governo, para enganar os cidadãos, cercá-los e confiná-los às suas definições de sociedade da informação e do conhecimento, quando se sabe que grande parte da população não tem acesso à informação.

No Brasil, as múltiplas interações que os sujeitos mantêm com o mundo e com os outros sujeitos mostram que eles estão, quase sempre, submetidos à desinformação ou pouca informação. Morin (1995) ilustra muito bem essa questão da "subinformação", quando diz que percebe, nas interações dos sujeitos, algumas zonas de sombra informacional que produzem ruídos e redundâncias e operam para que não se saiba o que acontece em determinados lugares.

Já a "superinformação" (MORIN, 1995) é o que se denomina hoje "universalização da informação" (TAKAHASHI, 2000), subsidiada pelos programas governamentais, cuja dinâmica estabelece um nexo com a "informação-ficção" (MORIN, 1995). Entretanto, a universalização da informação só terá efeito democrático, se houver a participação efetiva de todos os cidadãos no espaço público. Ela agregará valor, quando os sujeitos puderem transformá-la em conhecimento crítico em uma ação partilhada com o outro, produzindo um conhecimento que sirva para libertar outros sujeitos, grupos humanos, comunidades e nações.

A CI pode ampliar os cenários de referências teóricas e práticas, a partir de ações de informação que visem ao fortalecimento de seus fundamentos e espaços de produção acadêmico-informacional, com vistas à inclusão social, avançando em relação ao tratamento que convencionalmente tem sido dado às questões informacionais de modo a lidar com a diversidade cultural, a marginalidade, a violência e a discriminação social. Enquanto disseminadores da cultura informacional, os professores-pesquisadores, nos cursos de formação de "profissionais que pensam-conhecem-agem sobre a informação" (AQUINO, 2006, p.2), junto com as coisas que fazem ou deveriam fazer, deveriam exercitar o conhecimento reflexivo, pois, assim, podem ajudar a disciplinar e policiar essa fronteira da não-inclusão do outro, visto que nos conflitos existem pontos de resistência, estratégias e táticas e momentos de superação nas lutas.

Essas lutas ocorrem em linhas complexas de resistência e aceitação, de recusa e capitulação, transformando o campo da informação "em uma espécie de campo de batalha permanente, onde não se obtêm vitórias definitivas, mas onde há sempre posições estratégicas a serem conquistadas ou perdidas" (HALL, 2003, p. 255-259). Esse é um procedimento normal a ser aplicado para perspectivas que ainda defendem uma teoria da informação mecânica, a qual necessita de revisões em seus vários aspectos.
Nesse novo século, as ciências e, de modo específico, a CI necessitam de uma teoria cujo potencial de estímulo ainda não esteja esgotado (CAPURRO, 2003). O desafio que se coloca para a atividade científica não é o da separação do objeto do conhecimento ou o sujeito do conhecimento, mas a busca por uma cultura científica que se opõe a qualquer forma de reducionismo e determinismo e que, para além do pensamento simplificador, procura alimentar a reflexibilidade sobre os problemas gerais, globais e locais (MORIN, 1999b).

A qualidade de ciência social que caracteriza a CI implicaria uma reformulação densa de seus fundamentos e da concepção do que se entende por informação social e sujeitos da informação. Sem desconsiderar a sua especificidade, entendemos que o movimento de construção de uma "nova ciência" da informação postula cada vez mais o estreitamento de seus laços sociais e culturais na produção do conhecimento, pois a disjunção peculiar ao conhecimento científico dificulta o diálogo entre as ciências e a possibilidade de "um conhecimento do conhecimento" (MORIN, 1999b, p. 21) voltado para o social.

Do mesmo modo, a CI, que se constitui nas práticas disciplinares e específicas, precisaria capturar o conhecimento produzido por outras ciências para reter o conhecimento amplo, refinando-o para a atualização de seus fundamentos teóricos e sociais. Essa orientação não é nova, porquanto Wersig (1993) já sugeria a "redefinição de conceitos científicos amplos" no campo da $\mathrm{CI}$, em que se confrontariam esses novos conceitos com o atual contexto, as implicações e a pertinência deles nas suas teorias e práticas.

Tal possibilidade está implícita na abordagem complexa, que nos ajuda a pensar a reflexão filosófica como uma necessidade para relacionar, relativizar e historicizar o conhecimento produzido, que, neste século, impõe também novas exigências cognitivas, refazendo a compreensão da ordem shannoniana, em que se idealiza a informação, enquanto uma grandeza observável e mensurável dissemina um conhecimento dissociado da significação, da qualidade, do valor e da contribuição da informação para o receptor assumir seu papel social.

Essa forma de conceber a informação mostra sua estreita relação com o desenvolvimento das ciências exatas, em que se separa o sujeito do objeto, deixando-o sem qualquer comunicação com o social. Em contrapartida, "começa-se a compreender, desde então, [que] nem a verificação empírica nem a verificação lógica são suficientes para estabelecer um fundamento seguro ao conhecimento" (MORIN, 1999, p. 25).

Embora diversos trabalhos na CI venham sinalizando para a construção de uma "nova ciência" da informação, as novas pesquisas precisam sugerir o envolvimento de seus pesquisadores com a complexidade do mundo, para (re) ligar, concretamente, as ciências sociais e aplicadas às temáticas, tais como planetariedade, globalização, 
sustentatibilidade, biodiversidade, virtualidade, interatividade, transdisciplinaridade, ecodesenvolvimento, regionalização, eticidade, transculturalidade, transversalidade, dialogicidade, comunicabilidade, subjetividade, cotidianidade, diversidade, multiculturalidade, sem esquecer as relações de gênero, sexualidade, raça e etnia, a fim de extrair as possibilidades para pensarmos as suas relações com a informação.

Compreender o papel social da CI ante o novo modelo de ciência na sociedade da informação e do conhecimento é dar visibilidade à natureza do conhecimento científico produzido em nível local e global. É preciso dissociar esse conhecimento da racionalidade, que vai difundir a ciência sem consciência dos problemas e solução de sua própria complexidade, presente na relação de cada ser humano que ele produz e que o produz (MORIN, 2000). Isso implicaria a necessidade de analisarmos a CI e sua interação com outras ciências e atores sociais, tendo como eixo a compreensão de seu papel na resolução de problemas sociais com os quais os indivíduos se deparam no mundo das coisas ou no mundo da vida. O papel do pesquisador da CI seria o de assumir atitude que interroga a pretensa neutralidade, o perigo que representa, a responsabilidade política e social e o poder de que se investe, a fim de levantar bandeiras a favor da superação da dicotomia ciência/sociedade, porque o fazer da ciência implica uma reflexão filosófica para conferir firmeza e consistência aos princípios que a própria ciência estabelece.

O espírito desse novo tempo está colocando em dúvida não apenas as certezas e as utopias, mas também a busca da possibilidade de reunir a informação e o conhecimento em permanente intercomunicação diante das incertezas que povoam o território da ciência, advogando a liberdade de refletir as necessidades humanas, a partir da multidimensionalidade dos objetos, das teorias e das práticas da ciência. Assim,

para recolocá-la na ordem do dia, é necessário rever a própria definição de ciência, seus limites como campo de conhecimento, seus métodos, suas técnicas e tecnologias (ARAÚJO, 2003, p. 1).

Na linguagem moriniana, fazer ciência social traz subentendida a idéia de complicação, desordem, contradição, dificuldade lógica, problemas de organização e outros elementos que formam o tecido da complexidade, o qual não anula inteiramente as formas tradicionais de produção do conhecimento, mas ajuda a fortalecer a necessidade de um diálogo mais salutar com outras formas de conhecimento.

Diante de tantos avanços e paradoxos, como pensar estratégias para atores sociais fortalecerem a identidade da CI como uma ciência social e aplicada nesse novo modo de desenvolvimento?
$\mathrm{Na}$ busca de uma resposta à questão, Capurro (2003) e González de Gómez (2002) para apontam uma infovia possível: o caráter social da Ciência da Informação. Para esses estudiosos, a informação não seria mais o produto final de representação, ou algo que está sendo transportado de uma mente a outra, ou, finalmente, algo separado de uma subjetividade encapsulada, mas sim, uma dimensão existencial do nosso "estar-no mundo-com-os-outros".

A dimensão existencial, segundo Capurro (2003), revela uma característica eminentemente social, um caráter social e pragmático, que pressupõe uma relação entre sujeitos, uma "ação de informação", considerando que só tem sentido falar de um conhecimento como informativo em relação a um suposto conhecimento compartilhado com outros, com relação ao qual a informação pode ter um caráter de ser nova e relevante para um grupo ou para um indivíduo. Concordamos, pois, com essa tendência de conceber a informação como uma dimensão das práticas e interações do sujeito, situado no mundo junto com outros sujeitos. Esse ponto de vista é validado por González de Gòmez (2002), quando diz que se trata de a CI demarcar o seu domínio no contexto das ações sociais. Esse modo de pensar, em nosso ponto de vista, traduz uma forma de inclusão social por meio da ação informacional ou inclusão informacional para grupos que vivem em situações de exclusão.

Essa forma de pensar a informação como uma ação dos sujeitos no mundo, junto a outros homens, significa articular-se com uma compreensão de um mundo comum compartilhado, uma dimensão existencial de nosso ser no mundo junto com os outros. Essa natureza relacional do ser humano se aproxima do pensamento freireano, que vê a possibilidade de uma pluralidade de relações do homem com o mundo e com os outros, à medida que responde a ampla variedade de desafios. Sua visão humanizadora distingue a condição genuinamente humana de existir da condição animal de viver, que também é característica dos humanos, mas existir ultrapassa o viver porque é mais do que estar com/no mundo. É estar nele/com ele/com os outros. $\mathrm{O}$ ser humano é um ser que se faz em suas relações no mundo, com o mundo e com os outros (ROMÃO, 2002).

A visão de Capurro (2003) de conceber a informação como uma prática social nos aproxima de Paulo Freire, quando este defende a possibilidade de formação de um ator social crítico e autônomo, capaz de conviver com os conflitos e as perplexidades sem perder a fé na reconstrução de uma sociedade mais justa e igualitária. É visível, no trabalho de Paulo Freire, a sua preocupação com o sujeito no sentido de situá-lo como criador da história e da cultura, da informação e do conhecimento. Ao realçar a capacidade desse sujeito de conviver com a pluralidade, Freire observa que essa possibilidade vai se dar pela forma como esse sujeito capta os dados de sua realidade. Mas isso implica um processo de conscientização, desviando da consciência ingênua para alcançar a consciência crítica. 
O pensar reconstrutivo supõe um processo que

consiste no desenvolvimento crítico da tomada de consciência [...] pois, quanto mais conscientizados nos tornamos, mais capacitados estamos para ser anunciadores e denunciadores, graças ao compromisso de transformação que assumimos (FREIRE, 1990, p. 26-28).

Pensar reconstrutivamente é uma posição que nós devemos assumir permanentemente. Nesse sentido de um pensar reconstrutivo, Brenannd (2006) retoma e atualiza o pensamento freireano, sintetizando as três formas de consciência propostas por esse educador.

A primeira - "consciência ingênua ou intransitiva" - é a consciência humana no grau mais elementar de seu desenvolvimento em que a centralização dos interesses gira em torno de formas vegetativas de vida. As preocupações do sujeito se voltam para o que há nele de vital, biológico. Faltalhe teor de vida no plano histórico. Pela consciência ingênua, os indivíduos vêem a realidade dos fatos como algo estático, já feito e estabelecido. Domina-os de fora, percebe os fenômenos, mas não se coloca a distância para julgá-los e por isso se considera livre para entendê-los, conforme melhor lhe parecer e, assim, sobrepõe-se à realidade. A patologia da ingenuidade leva à irracionalidade, ao ajustamento e à acomodação. O que caracteriza a consciência intransitiva é a falta de motivação, a ausência de compromisso, a dificuldade de discernimento, interpretação mágica da realidade. Ao contrário, a consciência crítica desenvolve constantemente a capacidade de revisões e reinterpretações, a segurança na argumentação, a facilidade para o diálogo, abertura à transformação.

A segunda é a "consciência mágica", que se faz presente quando os indivíduos detêm uma concepção mística do mundo. Essa consciência mágica faz com que eles captem os fatos, emprestando-lhes um poder superior. Dominam-nos de fora, submetendo-se a eles com docilidade, com fatalismo e, às vezes, com fanatismo. Cruzam os braços porque se consideram incapazes de fazer algo diante do poder dos fatos. A "consciência transitiva" caracteriza-se ainda por forte dose de espiritualidade, mas começa a se alargar acima dos interesses vegetativos. Há, ainda, simplicidade na interpretação dos fatos e forte inclinação ao gregarismo característico da massificação. Esses indivíduos têm uma tendência à transferência de responsabilidade e autoridade, desconfiam do novo e preferem a polêmica ao debate, pois sua argumentação é frágil.

Na terceira, a "consciência crítica", os indivíduos captam e percebem os fatos conseguindo desocultar as razões que os explicam e são capazes de compreender seus nexos causais e circunstanciais. Com a capacidade de desvelar a realidade, são conduzidos à sua vocação ontológica de humanizar-se. A "consciência crítica" fundamenta a criatividade e estimula a reflexão, dando origem a ações verdadeiras sobre a realidade.
São pessoas inquietas e que buscam, constantemente, a ação social transformadora.

Os três estágios da consciência apresentados podem variar, não somente em função da idade ou da experiência. Admitimos que a informação estratégica vai se tornar um dos elementos fundamentais no processo de conscientização, posto que permite ao sujeito passar de um estágio a outro de consciência e, conseqüentemente, da "subinformação" ou "superinformação" (MORIN, 1995) para a informação social, o que vai afetar a qualidade da ação de informação.

Mas, para isso, os sujeitos precisam observar a pertinência da informação que está sendo disseminada, democratizada, porquanto ela só faz sentido se quem a procura tiver interesse nela, já que aceitamos, tal qual Fayard (2000), a impossibilidade da disseminação e democratização da informação a não ser em relação a uma tensão, a uma espera, ou a uma base: a surpresa. É daí que nasce a "tensão interna", que orienta a vigilância e a disponibilidade em relação ao desenvolvimento de uma ação social de informação. O que está em jogo é a estratégia na construção do projeto de ação. A informação nova alimenta a compreensão, visando à ação social de informação, uma vez que é a pertinência estratégica em relação a um projeto que dá valor à informação (FAYARD, 2000).

A informação pode ser vista como um elemento privilegiado para desenvolvimento da consciência crítica nas atuais sociedades, nas quais os indivíduos se encontram em uma quase " aderência » ou « imersão " na realidade objetiva. A « cultura do silêncio », oriunda dos impactos das transformações econômicas, começa a ser « rachada ", e a consciência intransitiva começa a marchar para a transitividade impulsionada pelas contradições. Esse, talvez, seria o momento adequado para se iniciar uma ação informacional caracterizada pelo diálogo, a fim de impulsionar os não incluídos a compreender criticamente sua realidade. Nessa ação, não se admite a transferência de um conhecimento « neutro » mistificador, uma estratégia comum aos grupos que detêm a ciência e a tecnologia sob o seu comando, mas a conscientização dos grupos marginalizados pode ajudá-los a perceber que os avanços econômicos, científicos e tecnológicos são necessários ao desenvolvimento humano.

Essa conscientização, segundo Paulo Freire, é um esforço por meio do qual a consciência intransitiva é levada a perceber o mundo objetivo e social, a receber a informação e a recriá-la, transformando-a em conhecimento. Entretanto, o processo de conhecer e gerar conhecimento implica a constante açãoreflexão sobre a realidade em que o sujeito está inserido. A conscientização é o desenvolvimento crítico da tomada de consciência e comporta superar a fase espontânea da apreensão até alcançar um nível que, nessa realidade, tornase objeto cognoscível. É um processo em que o sujeito assume o posicionamento epistemológico da procura de conhecer, o 
qual se realiza na realização dialética indivíduo-mundo. Essa dimensão epistemológica não pode existir fora do ato de agirrefletir. A conscientização tem por finalidade descortinar as situações-limite nas quais os temas são bloqueados, tornando possível uma visão crítica sobre os mesmos.

Ao preocupar-se com a formação da consciência crítica, Freire (1982) visualiza o diálogo como uma possibilidade de ser exercitado pelos grupos marginalizados que, não estando inseridos no processo de aquisição da informação, ainda guardam suas atitudes mágicas ou ingênuas. É possível buscar essa integração no plano da relação ensinante/aprendente, por meio de um diálogo livre, em que ambos se coloquem como intérpretes, pesquisadores e decodificadores do real. Conscientizar é assumir um compromisso histórico, inserir-se criticamente na história;

implica que os homens assumam o papel de sujeitos que fazem e refazem o mundo. Exige que os homens criem sua existência com o material que a vida lhes oferece (FREIRE, 1990, p. 26)

Os pressupostos freireanos ajudam-nos a argumentar que a CI tem conexões fundamentais com a idéia de emancipação humana, mostrando-nos que a matriz que atribui sentido à prática informacional (ensino da informação) "é a visão de liberdade que [...] não pode ser efetiva e eficaz senão na medida em que os educandos nela tomem parte de maneira livre e crítica" (FREIRE, 1990, p. 50). Mas entendemos que qualquer prática informacional deverá adotar como princípio a participação livre dos cidadãos na conquista da informação, e o diálogo é a condição essencial dessa tarefa.

Freire (1982) propõe a linguagem dos indivíduos, carregada da experiência vivida, como material para início da descoberta de novas palavras e significados. A palavra não existe independente de sua significação real e de sua referência às situações experienciadas no mundo da vida. $\mathrm{O}$ espaço vivido é o lugar privilegiado para se promover o diálogo entre diferentes grupos e, sobretudo, para dar voz à grande parcela de crianças, jovens e adultos (negros, índios, ciganos, homossexuais, judeus) que vivem à margem dos processos educativos e informacionais. Na visão freireana, o diálogo é um instrumento importante para a superação da consciência ingênua e da construção de uma concepção descentrada de mundo. Pela ação-reflexão, proporcionada pelo diálogo, é possível compreender o real que se coloca como dado.

Na concepção de Freire (1982), o processo de interação permite aos sujeitos a construção de uma "arqueologia do conhecimento" no qual seja possível interrogar sua própria estrutura e a do conhecimento do outro, buscando clarificar sua consciência. O diálogo vai instigar a consciência asfixiada pela força da opressão e incentivar a emergência da compreensão da condição social de cada sujeito.

\section{CONSIDERAÇÕES FINAIS}

A dinâmica estrutural do mundo vivido passa por mudanças radicais em função da crescente complexidade do mundo social, da crescente explosão de informações. Os grupos sociais e as instituições estão se organizando em torno do processo de globalização cultural, social, política e econômica, reorganizando, reestruturando e hierarquizando uma pluralidade de saberes e de formas específicas de conhecimento. Assim, a compreensão analítica da teia que compõe essa rede permite a busca de novos indicadores para o fortalecimento do ato informacional. Novos canais para o desenvolvimento de diálogos múltiplos e multifacetados, necessários para os atores potencializarem novas formas de recriar as cenas informacionais em suas relações inter e transdisciplinares, estão abertos.

Mesmo que estejamos, no cotidiano e nas salas de aula, conectados à sociedade em rede pela multiplicidade de ferramentas hoje colocadas à nossa disposição pelas tecnologias da informação e comunicação, como computadores, redes de informação, televisão, vídeo, fax etc., não podemos deixar de pensar na formação de sujeitos humanos. Nesse sentido, o diálogo deverá ser considerado uma ferramenta importante para a construção de sujeitos capazes de fala e de ação.

Podemos sinalizar se somos favoráveis ou não à invasão das tecnologias da informação e comunicação no processo de formação, mas chegou o momento de nós, profissionais da informação, que temos o conhecimento e a informação como nossas matérias-primas, enfrentarmos os desafios oriundos das TICs. Esses enfrentamentos não significam a adesão incondicional ou a oposição radical ao ambiente eletrônico, mas, ao contrário, significa criticamente conhecê-los para saber de suas vantagens e desvantagens, de seus riscos e possibilidades, para, então, transformá-los em ferramentas e parceiros, em alguns momentos, e dispensá-los, em outros instantes.

A apreensão do conhecimento, na perspectiva das tecnologias eletrônicas de comunicação e informação, ao ser assumida como possibilidade didática, exige que, em termos metodológicos, também se oriente a prática informacional a partir de uma nova lógica. A solução concreta está em mudarmos as nossas visões de mundo, e não, apenas, as nossas posturas teóricas. Compreender este novo mundo com uma nova lógica, uma nova cultura, uma nova sensibilidade, uma nova percepção. Não mais, apenas, a perspectiva estrutural e linear de apresentação e desenvolvimento metodológico do conteúdo a ser ensinado, tampouco a exclusiva perspectiva de transferir informação, mas outra lógica, baseada na exploração de novos tipos de raciocínios nada excludentes, em que se enfatizem variadas possibilidades de encaminhamento das reflexões que estimulem a possibilidade de outras relações entre áreas do conhecimento aparentemente distintas. 
Supõe-se que o ensinante (professor), antes de tudo, deve posicionar-se não mais como o detentor do monopólio do saber, mas como um parceiro, no sentido clássico do termo, que encaminhe e oriente o aprendente (aluno) diante das múltiplas possibilidades e formas de alcançar o conhecimento e de se relacionar com ele. $\mathrm{O}$ sentido etimológico do saber significa caminhar com o aprendente em direção às diversas fontes do saber. Até agora, existiam lugares de saber, um campus, uma biblioteca, um laboratório. Com os novos meios, é o saber que navega.

A informação e o conhecimento são essencialmente criações humanas, e nunca seremos capazes de processá-los ou interpretá-los, se não levarmos em consideração que os

\section{REFERÊNCIAS}

AQUINO, M. A. A construção do currículo em parceria com o projeto educativo. Informação $\mathcal{E}$ Informação, Londrina, v. 11, n. 1, jan./jun. 2006. Disponível em: < http:// www.uel.br/revistas/informacao/viewissue.php?id=33> Acesso: 21 out. 2006.

ARAÚJO, C. A. A. A ciência da informação como ciência social. Ciência da Informação, v. 32, n. 3, p. 21-27, set./dez. 2003.

BAUDRILLARD, Jean. As estratégias fatais. Lisboa: Editorial Estampa, 1990.

BRENNAND, E. G. G (Org.). O labirinto da educação popular. João Pessoa: EDUFPB, 2003.

CAPURRO, R. Epistemologia e ciência da informação. 2003. Disponível em: < http:// www.capurro.de/enancib.ppt>. Acesso em: 05 jun. 2004.

CASTELLS, M. A sociedade em rede. São Paulo: Paz e Terra, 1999. V. 1.

DELEUZE, G.; GUATTARI, F. Mil platôs. Rio de Janeiro: Editora 34, 1995. V. 1.

DELORS, Jacques. Educação: um tesouro a descobrir: relatório da Comissão Internacional sobre a Educação para o século XXI. Cortez: São Paulo, 1999.

FAYARD, P. O jogo da interação: informação e comunicação em estratégia. Caxias do Sul: EDURCS, 2000.

FREIRE, P. Educação como prática da liberdade. Rio de Janeiro: Paz e Terra, 1982.

Conscientização: teoria e prática da libertação: uma introdução ao pensamento de Paulo Freire. São Paulo: Moraes, 1990.

GIROUX, H. O pós-modernismo e o discurso da crítica educacional. In: SILVA, Tadeu Tomas da (Org.). Teoria educacional crítica em tempos pós-modernos. [S.l.]: Artes Médicas, 1993. sujeitos desempenham nesse cenário um papel fundamental: suas necessidades sociais. Essa visão ajuda-nos a sintetizar a idéia de uma ciência de natureza social, que deve considerar, em seus estudos e pesquisas, o modo como os sujeitos criam, distribuem, compreendem e usam a informação e se esses sujeitos estão incluídos socialmente nessa disseminação da informação para transformá-la em conhecimento.

\section{Artigo recebido em 14/11/2007} e aceito para publicação em 16/05/2008

HALL, S. Da diáspora: identidades e mediações culturais. Belo Horizonte: UFMG, 2003.

JAMERSON, F. Pós-modernismo: a lógica cultural do capitalismo tardio. São Paulo: Àtica, 1996.

LASTRES, H. M. M.; ALBAGLI, S. Chaves para o terceiro milênio na era do conhecimento. In: Janeiro: Campus, 1999. Informação e globalização na era do conhecimento. Rio de

LYOTARD, J. F. A condição pós-moderna. Lisboa: Gradiva, 1989.

MORIN, E. A cabeça bem feita: repensar a reforma, reformar o pensamento. Rio de Janeiro: Bertrand do Brasil, 2000. . Ciência com consciência. Rio de Janeiro: Bertrand do Brasil, 1999a. 1999b. . O método 3: o conhecimento do conhecimento. Porto Alegre: Sulina Para sair do século XX. Rio de Janeiro: Nova Fronteira, 1995.

PINHEIRO, L. V. Informação: esse obscuro objeto da ciência da informação. Disponível em: <http://www.unirio.br/morpheusonline/Numero04-2004/lpinheiro.htm>. Acesso em: 14 mar. 2006.

ROMÃO, J. E. Pedagogia dialógica. São Paulo: Cortez, 2002.

TAKAHASHI, T. (Org.). Sociedade da informação no Brasil: livro verde. Brasília: Ministério da Ciência e Tecnologia, 2000.

WERSIG, G. Information science: the study of postmodern knowledge usage. Information Processing $\mathcal{E}$ Management, v. 29, n. 2, 1993.

SARACEVIC, T. A educação em ciência da informação na década de 80. Ciência da Informação, Brasília, v. 7, n. 3, p. 3-12, 1978. 